\title{
Soybean products and reduction of breast cancer risk: a case- control study in Japan
}

\section{K Hirose, ${ }^{*,}$, N Imaeda ${ }^{2}$, Y Tokudome ${ }^{3}$, C Goto ${ }^{3}$, K Wakai', K Matsuo', H Ito', T Toyama $^{4}$ H Iwata ${ }^{4}$, S Tokudome ${ }^{5}$ and $K$ Tajima'}

'Division of Epidemiology and Prevention, Aichi Cancer Center Research Institute, I-I Kanokoden Chikusa-ku, Nagoya 464-868 I, Japan; ${ }^{2}$ Nagoya Women's University, Mizuho-ku, Nagoya 467-8610, Japan; ${ }^{3}$ Nagoya Bunri University, Inazawa 492-8520, Japan; ${ }^{4}$ Department of Breast Surgery, Aichi Cancer Center Hospital, I-I Kanokoden, Chikusa-ku, Nagoya 464-868I, Japan; ${ }^{5}$ Department of Health Promotion and Preventive Medicine, Nagoya City University Graduate School of Medical Science, Mizuho-ku, Nagoya 467-860 I, Japan

\begin{abstract}
Components of the Japanese diet, which might contribute to the relatively low breast cancer incidence rates in Japan, have not been clarified in detail. Since soybean products are widely consumed in Japan, a case-control study taking account of the menopausal status was conducted using data from the hospital-based epidemiologic research program at Aichi Cancer Center (HERPACC). In total, 167 breast cancer cases were included and 854 women confirmed as free of cancer were recruited as the control group. Odds ratios $(\mathrm{OR})$ and $95 \%$ confidence intervals $(95 \% \mathrm{Cl}$ ) were determined by multiple logistic regression analysis. There were reductions in risk of breast cancer associated with high intake of soybean products among premenopausal women. Compared with women in the lowest tertile, the adjusted ORs for top tertile intake of tofu (soybean curd) was $0.49(95 \% \mathrm{Cl}, 0.25-0.95)$. A significant decrease in premenopausal breast cancer risk was also observed for increasing consumption of isoflavones $(\mathrm{OR}=0.44 ; 95 \% \mathrm{Cl}, 0.22-0.89$ for highest vs lowest tertile; $P$ for trend =0.02). The present study found a statistically inverse association between tofu or isoflavone intake and risk of breast cancer in Japanese premenopausal women, while no statistically significant association was evident with the risk among postmenopausal women.

British Journal of Cancer (2005) 93, I5-22. doi:10.1038/sj.bjc.6602659 www.bjcancer.com
\end{abstract}

Published online 7 June 2005

(c) 2005 Cancer Research UK

Keywords: soybean products; isoflavones; menopausal status

Despite a marked increase in recent years, the incidence rates for female breast cancer in most Asian countries are much lower than those in the Western world (Parkin et al, 1997). Much of the international variation is due to differences in established reproductive risk factors, such as age at menarche, parity and age at first birth, but dietary habits might also contribute. Dietary studies of breast cancer have typically focused on the hypothesis that there is a positive link with intake of fat. While ecological studies have suggested associations in terms of incidence and mortality, leading prospective studies of breast cancer, including the Nurse's Health Study (Stampfer et al, 1987) and studies of large cohorts from New York (Toniolo et al, 1994) and Norway (Vatten et al, 1990) have shown no relation (Willett, 1997). Recently, there has been more interest in other dietary factors, such as soybean products, which may protect against breast cancer and provide an explanation for some of the international differences in incidence rates (Adlercreutz, 1990; Messina and Barnes, 1991).

Soybeans provide a unique concentrated source of isoflavones and soybeans or isoflavones have been shown to exert anticarcinogenic effects on hormone-related cancers in a large number of experimental studies. Despite the growing interest in the protective effects, there are relatively few epidemiological data available since soybean products are consumed mainly by Asian

*Correspondence: Dr K Hirose; E-mail: khirose@aichi-cc.jp Received 21 February 2005; revised 9 May 2005; accepted 9 May 2005; published online 7 June 2005 populations. In Japan, intake is in various forms, including tofu (soybean curd), okara (tofu lees), moyashi (soybean sprouts), tonyu (soymilk), yuba (soy milk skin), kinako (soy flour), miso (fermented soybean paste), atsuage (deep fried tofu), aburage (thinly sliced deep fried tofu), natto (fermented soybeans), koyadofu (freeze dried tofu) and shoyu (soy sauce), so that the diet is likely to be much richer in isoflavones than in the Western world, where the diet usually does not include soybeans. We here evaluated the association between risk of breast cancer and consumption of soybean products and isoflavones using data from the hospital-based epidemiologic research program at Aichi Cancer Center (HERPACC).

\section{MATERIALS AND METHODS}

\section{Data collection}

Details of the study design and subject characteristics have been described elsewhere (Yoo et al, 1992; Hirose et al, 1995, 1999, 2001). In brief, we have conducted the HERPACC study since 1988, whereby questionnaire survey is completed by first-visit outpatients to the Aichi Cancer Center Hospital (ACCH) (Tajima et al, 2000). All questionnaires are then collected after checking for incomplete responses by a trained interviewer and the data are loaded into the computer system of the Aichi Cancer Center Research Institute. The data collected are linked with the 


\section{6}

hospital-based cancer registry files. This study was approved by the Institutional Review Board, and all participants provided written, informed consent.

The questionnaire included questions on occupation, medical history, height, weight, weight at around 20 years of age, family history (parents and siblings), smoking and drinking habits, sleeping habits, physical exercise and reproductive history. The details were taken prior to assessment of symptoms and all information was collected before clinical diagnoses were made.

\section{Cases and controls}

The present analysis was restricted to women aged 30 and over who visited hospitals between January 2001 and March 2002. As eligible cases, 79 premenopausal and 88 postmenopausal women diagnosed as having breast cancer by histological examination within 6 months of the first-visit were recruited. A methodological study applying the same HERPACC data set earlier showed that the OR based on a large number of controls gives more power and steadier estimates than the use of matched controls (Hamajima et al, 1994); therefore, we used all noncancer individuals as candidates for controls in this study. As the controls, 854 female first-visit outpatients who had never been diagnosed as having cancer were recruited. Table 1 summarises details for the 167 cases and 854 controls by age group and selected characteristics.

\section{Exposure data}

The interview included a validated, semiquantitative foodfrequency questionnaire (FFQ) (Tokudome et al, 1998, 2001; Imaeda et al, 2002). Dietary intake was ascertained using a detailed quantitative FFQ, including 119 food items/recipes, and the following food groups were included: (a) meat and meat products (poultry, ground meat, pork meat, beef, ham, sausage, bacon, liver); (b) fish and fish products (salmon, eel, pale blue fleshed fish, red fleshed fish, white fleshed fish, squid, octopus, shrimp, crab, dried fish larvae, small bony fish, tuna canned in oil, cod roe, oyster, shellfish, dried squid, fried fish paste, fish paste sausage); (c) green-yellow vegetables (green leafy vegetables, pumpkin, carrot, broccoli, green pepper, green soybean, green beans, tomato); (d) other vegetables (cabbage, Japanese radish, burdock, bamboo shoots, cucumber, eggplant, lettuce, bean sprout, onion, Chinese cabbage, Japanese radish); (e) fruits (oranges, mandarin oranges, persimmon, banana, apple, strawberries, kiwi, peach, grapes, watermelon, melon, Japanese pears); (f) dairy products (low fat milk, medium fat milk, high fat milk, calcium enriched milk and yoghurt, skim milk, lactic acid bacteria beverage, yoghurt, cheese, ice cream).

Furthermore, the following soybean products were included: (a) tofu (soybean curd); (b) miso (fermented soybean paste); (c) atsuage (deep fried tofu); (d) aburage (thinly sliced deep fried tofu); (e) natto (fermented soybeans); (f) koyadofu (freeze dried tofu). We evaluated validity of intakes based on the questionnaire against those according to 28-day (four-season consecutive 7-day) weighted diet records among 79 Japanese female dietitians. In the validation study, the Spearman's correlation coefficients between the estimate intake of soybean products and isoflavone from the questionnaire and that from dietary records were $0.51,0.53$, respectively. For reproducibility of estimation from the questionnaire, the Spearman's correlation coefficients for the consumption of soybean products and isoflavone intake between two questionnaires administered 1 year apart were 0.57 and 0.47 , respectively.

All subjects in the present study were asked for average frequency and portion size of consumption, during the period of 1 year before onset of the present disease or before the interview. There were eight categories of possible responses, ranging from 'rarely or never' to 'three or more times per day'. For each food, a
Table I Basic characteristics of cases and controls

\begin{tabular}{|c|c|c|}
\hline & $\begin{array}{c}\text { Cases } \\
(n=167)\end{array}$ & $\begin{array}{l}\text { Controls } \\
(n=854)\end{array}$ \\
\hline \multicolumn{3}{|l|}{ Age (years) } \\
\hline $30-39$ & $19(11.4 \%)$ & $99(11.6 \%)$ \\
\hline $40-49$ & $46(27.5 \%)$ & $279(32.7 \%)$ \\
\hline $50-59$ & $54(32.3 \%)$ & $280(32.8 \%)$ \\
\hline$\geqslant 60$ & $48(28.7 \%)$ & $196(23.0 \%)$ \\
\hline Mean age (s.d.) & $52.7(10.2)$ & $51.4(10.5)$ \\
\hline \multicolumn{3}{|l|}{ Motives for consultation } \\
\hline Self-recommendation & $47(28.1 \%)$ & $286(33.5 \%)$ \\
\hline Family recommendation & $43(25.8 \%)$ & $194(22.7 \%)$ \\
\hline Referral from other clinics & $44(26.4 \%)$ & $139(16.3 \%)$ \\
\hline Secondary screening after primary screening & $33(19.8 \%)$ & $224(26.2 \%)$ \\
\hline Others & $0(0.0 \%)$ & $6(0.7 \%)$ \\
\hline Unknown & $0(0.0 \%)$ & $5(0.6 \%)$ \\
\hline \multicolumn{3}{|l|}{ Smoking status } \\
\hline Never & $146(87.4 \%)$ & $710(83.2 \%)$ \\
\hline Ever & $9(5.4 \%)$ & $51(6.0 \%)$ \\
\hline Current & $12(7.2 \%)$ & $91(10.7 \%)$ \\
\hline Unknown & $0(0.0 \%)$ & I $(0.1 \%)$ \\
\hline \multicolumn{3}{|l|}{ Drinking status } \\
\hline Never & III (66.5\%) & $546(63.9 \%)$ \\
\hline Ever & $0(0.0 \%)$ & $13(1.5 \%)$ \\
\hline Current & $56(33.5 \%)$ & $295(34.5 \%)$ \\
\hline \multicolumn{3}{|l|}{ Exercise } \\
\hline No & $54(32.3 \%)$ & $291(34.1 \%)$ \\
\hline$\leqslant 60 \mathrm{~min} /$ week & $33(19.8 \%)$ & $192(22.5 \%)$ \\
\hline$\leqslant 120 \mathrm{~min} /$ week & $27(16.2 \%)$ & $126(14.8 \%)$ \\
\hline$>120 \mathrm{~min} /$ week & $47(28.1 \%)$ & $225(26.4 \%)$ \\
\hline Unknown & $6(3.6 \%)$ & $20(2.3 \%)$ \\
\hline Mean BMI (s.d.) & $22.9(3.1)$ & $22.0(3.0)$ \\
\hline Mean of age at first birth (s.d.) & $25.8(3.6)$ & $25.7(3.5)$ \\
\hline Mean of age at menarche (s.d.) & $13.5(1.5)$ & $13.4(1.6)$ \\
\hline \multicolumn{3}{|l|}{ Parity } \\
\hline Parous & $155(93.4 \%)$ & $763(89.7 \%)$ \\
\hline Nulliparous & $11(6.6 \%)$ & $88(10.3 \%)$ \\
\hline \multicolumn{3}{|l|}{ Menopausal status } \\
\hline Premenopausal & $79(47.3 \%)$ & $414(48.5 \%)$ \\
\hline Postmenopausal & $88(52.7 \%)$ & $440(51.5 \%)$ \\
\hline \multicolumn{3}{|l|}{$\begin{array}{l}\text { Age at menopause among postmenopausal } \\
\text { women }\end{array}$} \\
\hline$\leqslant 47$ & $24(27.3 \%)$ & 105 (23.9\%) \\
\hline $48-52$ & $42(47.7 \%)$ & $225(51.1 \%)$ \\
\hline$\geqslant 53$ & $22(25.0 \%)$ & 83 (18.9\%) \\
\hline Unknown & $0(0.0 \%)$ & $27(6.1 \%)$ \\
\hline \multicolumn{3}{|l|}{ Family history ${ }^{a}$} \\
\hline No & 153 (91.6\%) & $79 \mid(92.6 \%)$ \\
\hline Yes & $14(8.4 \%)$ & $63(7.4 \%)$ \\
\hline
\end{tabular}

s.d. $=$ standard deviation. ${ }^{\mathrm{a}}$ Family history in mother or sisters.

commonly used unit or portion size was specified and the interviewers asked the subjects using sampling models of fullscale photographs. We ascertained average amount of daily consumption of each food and nutrients by multiplying the food intake (in grams) or serving size and the nutrient content per 100 grams of food as listed in the Standard Tables of Food Composition, Version 5 and the Follow-up of Standard Tables of Food Composition (Science and Technology Agency, Japan, 1994, 2001). Isoflavone intakes were separately calculated from USDAIowa State University Database on the Isoflavone Content of 
Foods, Release 1.3-2002 (http://www.nal.usda.gov/fnic/foodcopm/ Data/isoflav/isoflav.html). Isoflavone intake was calculated using consumption of six items of soybean products, green soybean, peanuts, Japanese green tea, and vegetables other than greenyellow vegetables such as cucumber, eggplant, lettuce, bean sprouts, onion, Chinese cabbage.

\section{Statistical analysis}

Dietary intake data were analysed by individual food items, food groups and nutrients for all subjects combined and separately for premenopausal and postmenopausal women. The differences of means were examined by $t$-test and all $P$-values presented are two-sided.

Logistic regression analysis was used to obtain odds ratios (ORs) and $95 \%$ confidence intervals ( $95 \% \mathrm{CI}$ ) as estimates of relative risk. The $P$-value for trend corresponded to the estimate of the slope derived from the logistic model in the case that the integers, 1 to $n$, were assigned to the ordered $n$ levels of each factors. The LOGISTIC procedure provided by SAS (SAS Institute, Cary, NC, USA) was utilised to perform the calculations. To compare differences and similarities of effects of Japanese diet on risk for breast cancer, subjects were stratified with reference to menopausal status. The ORs of breast cancer are calculated for the selected food groups and isoflavone intake in tertiles, with the lowest tertile as the referents. Multivariate models was adjusted for age, energy (as a continuous variable), motives for consultation (self-recommendation, family recommendation, referral from other clinics, secondary screening after primary screening, others), smoking status (never, ever, current), drinking status (never, ever, current), exercise (none, $\leqslant 60 \mathrm{~min} /$ week, $\leqslant 120 \mathrm{~min} /$ week, $>120 \mathrm{~min} /$ week), family history (yes or no), age at menarche $(\leqslant 12,13, \geqslant 14)$, parity $(0,1,2,3+)$, age at first full-term pregnancy $(\leqslant 23,24-27, \geqslant 28)$, and current body mass index $(\mathrm{BMI})(\leqslant 20$,
$20-25, \geqslant 25)$. Further, inclusion in the model of age at menopause $(\leqslant 47,48-52, \geqslant 53)$ was performed with the calculations for postmenopausal women. Energy was adjusted for the multivariate nutrient density method.

A positive family history may involve different types and numbers of relatives. Distant relatives share less genetic influence and fewer confounding environmental and/or behavioral factors than do close ones. Furthermore, information on the medical history of distant relatives is limited and less precise than that of close or first-degree relatives. In this study, the presence of either a mother or sister with breast cancer was considered as a positive family history. BMI was calculated as weight $/ \mathrm{height}^{2}\left(\mathrm{~kg} \mathrm{~m}^{-2}\right)$, according to Quetelet's formula and current BMI values were stratified into three categories. Since a BMI $\geqslant 25$ is defined as obese by the Japanese Society for the Study of Obesity, the cutoff for the highest $\mathrm{BMI}$ group was $\mathrm{BMI} \geqslant 25$.

\section{RESULTS}

Table 2 summarises data for daily intake of some nutrients and consumption of selected food groups among cases and controls. There were no significant differences between cases and controls in intake of energy and fat. The means of meat and meat products intakes per day was $60.7 \mathrm{~g}$ (standard deviation (s.d.), $34.7 \mathrm{~g}$ ) and $67.0 \mathrm{~g}$ (s.d., $39.4 \mathrm{~g})$, respectively, for cases and controls $(P<0.04)$. Among premenopausal women, the means of soybean products were $51.7 \mathrm{~g}$ (s.d., $31.2 \mathrm{~g}$ ) in case group and $63.5 \mathrm{~g}$ (s.d., $38.8 \mathrm{~g}$ ) in control group $(P<0.01$, data not shown). Breast cancer cases reported lower total isoflavones intake per day than controls, with averages of $20.8 \mathrm{mg}$ (s.d., $10.8 \mathrm{mg}$ ) and $25.8 \mathrm{mg}$ (s.d., $14.3 \mathrm{mg}$ ), respectively $(P<0.0001$, data not shown) among premenopausal women. We observed no other significant differences among premenopausal women and there were no significant differences

Table 2 Distribution of selected dietary variables (intake/day) among breast cancer cases and controls

\begin{tabular}{|c|c|c|c|c|c|c|c|c|}
\hline \multirow[b]{3}{*}{ Nutritional factors and food items } & \multicolumn{4}{|c|}{ Cases } & \multicolumn{4}{|c|}{ Controls } \\
\hline & \multirow[b]{2}{*}{ Mean } & \multicolumn{3}{|c|}{ Percentile } & \multirow[b]{2}{*}{ Mean } & \multicolumn{3}{|c|}{ Percentile } \\
\hline & & 25 & 50 & 75 & & 25 & 50 & 75 \\
\hline \multicolumn{9}{|l|}{ Nutritional factors } \\
\hline Energy (kcal) & |83| & 1568 & |79| & 2038 & 1859 & 1593 & 1835 & 2093 \\
\hline Total protein (g) & 72.1 & 59.0 & 70.1 & 83.0 & 73.7 & 60.8 & 72.1 & 83.7 \\
\hline Total fat (g) & 57.5 & 43.5 & 55.0 & 70.6 & 59.1 & 45.5 & 57.9 & 70.4 \\
\hline$\%$ of energy (\%) & 27.9 & 25.0 & 28.7 & 31.4 & 28.4 & 24.3 & 28.5 & 32.3 \\
\hline Carbohydrate (g) & 252.9 & 220.8 & 243.6 & 279.7 & 254.7 & 217.5 & 249.8 & 289.7 \\
\hline Total dietary fibre (g) & 14.4 & 11.4 & 13.6 & 16.7 & 14.8 & $1 \mid .5$ & 14.2 & 17.2 \\
\hline Vitamin C (mg) & 161.5 & 115.6 & 152.1 & 194.4 & 164.9 & 108.4 & 146.3 & 199.3 \\
\hline Vitamin E (mg) & 10.1 & 7.9 & 9.7 & 12.1 & 10.3 & 8.1 & 10.0 & 12.1 \\
\hline Isoflavones (mg) & 24.8 & 15.3 & 21.3 & 30.3 & 27.1 & 17.0 & 24.2 & 32.5 \\
\hline \multicolumn{9}{|l|}{ Food items } \\
\hline Meat and meat products (g) & 60.7 & 36.4 & 55.7 & 77.9 & 67.0 & 38.6 & 61.6 & 90.0 \\
\hline Fish and fish products (g) & 56.5 & 38.9 & 52.9 & 68.6 & 56.8 & 36.0 & 52.9 & 71.4 \\
\hline Green-yellow vegetables (g) & 136.5 & 78.2 & 118.9 & 173.2 & 144.6 & 78.2 & 118.0 & 180.4 \\
\hline Other vegetables $(\mathrm{g})$ & 130.7 & 82.5 & $1 \mid 5.7$ & 154.3 & 135.8 & 88.2 & 125.4 & | 72.1 \\
\hline Fruit (g) & 164.5 & 83.4 & |42. | & 217.0 & | 67.1 & 84.1 & 143.3 & 219.7 \\
\hline Dairy products $(g)$ & 200.2 & 87.1 & 189.3 & 274.3 & 199.0 & 96.8 & 188.9 & 265.0 \\
\hline Soybean products $(\mathrm{g})$ & 63.4 & 35.5 & 53.5 & 82.4 & 67.7 & 39.5 & 60.5 & 84.3 \\
\hline Tofu (soybean curd) (g) & 39.0 & 20.0 & 29.0 & 50.0 & 41.7 & 23.0 & 35.0 & 52.0 \\
\hline Miso (fermented soybean paste) (g) & 6.3 & 2.0 & 5.0 & 10.0 & 7.1 & 5.0 & 8.0 & 10.0 \\
\hline Atsuage (deep fried tofu) (g) & 7.4 & 2.5 & 5.0 & 10.0 & 7.3 & 2.5 & 5.0 & 10.0 \\
\hline Aburage (thinly sliced deep fried tofu) (g) & 1.7 & 0.6 & 1.2 & 3.0 & 1.7 & 0.6 & 1.2 & 2.4 \\
\hline Natto (fermented soybeans) (g) & 9.2 & 4.0 & 7.2 & 10.0 & 10.3 & 4.0 & 8.0 & 16.0 \\
\hline Koyadofu (freeze dried tofu) (g) & 1.9 & 0.0 & 0.0 & 4.0 & 2.0 & 0.0 & 0.0 & 4.0 \\
\hline
\end{tabular}


between cases and controls in average intake of food groups and nutrients among postmenopausal women.

Among premenopausal women, breast cancer risk was inversely associated with consumption of soybean products (Table 3). The ORs was $0.53(95 \% \mathrm{CI}, 0.27-1.04)$ for the top tertile of soybean product intake compared with the lowest tertile of intake (trend test, $P=0.06$ ). Among postmenopausal women, on the other hand, consumptions of soybean products, meat and meat products, fish and fish products, vegetables, fruits, dairy products were not associated with the risk of breast cancer.

The ORs for breast cancer according to type of soybean product are presented in Table 4 . A statistically significant inverse relation was observed between tofu consumption and breast cancer in premenopausal women. ORs were 0.44 (95\% CI, 0.22-0.90), 0.49 (95\% CI, 0.25-0.95) for the second to the top tertiles of intake compared with the lowest tertile of intake of tofu (trend test, $P=0.03)$. Compared with those in the lowest tertile of atsuage (deep fried tofu) consumption, the adjusted OR for breast cancer in top tertile was 0.70 (95\% CI, $0.35-1.38)$ among premenopausal women. On the other hand, a significantly increased risk of breast cancer with consumption of atsuage was observed in postmenopausal women. The adjusted OR for top tertile of atsuage consumption was $2.28(95 \% \mathrm{CI}, 1.15-4.51$, trend test $P=0.02)$. Also, consumption of aburage (thinly sliced deep fried tofu) showed a similar positive association with the risk of breast cancer. There were no associations with intake of tofu, miso and natto intake among postmenopausal women. With intake of koyadofu (freeze dried tofu) divided into tertiles, there was no apparent modification of the breast cancer risk among either pre- or postmenopausal women.

We next determined the association between total intake of isoflavone and risk of breast cancer and found a statistically significant inverse association among premenopausal women. Compared with women in the lowest tertile of isoflavone consumption, the top tertile had an adjusted OR of 0.44 (95\% CI, $0.22-0.89$; trend test $P=0.02$ ). Among postmenopausal women the similar trend was also observed; however, there was no statistically significant association between consumption of isoflavone and breast cancer risk (Table 5).

\section{DISCUSSION}

The present study found a statistically inverse association between risk of breast cancer and soybean products (tofu) or isoflavones intake in Japanese premenopausal women while there was no statistically significant link among their postmenopausal counterparts.

Table 3 Odds ratios (ORs) and 95\% confidence intervals (Cls) for breast cancer according to food group intake by menopausal status

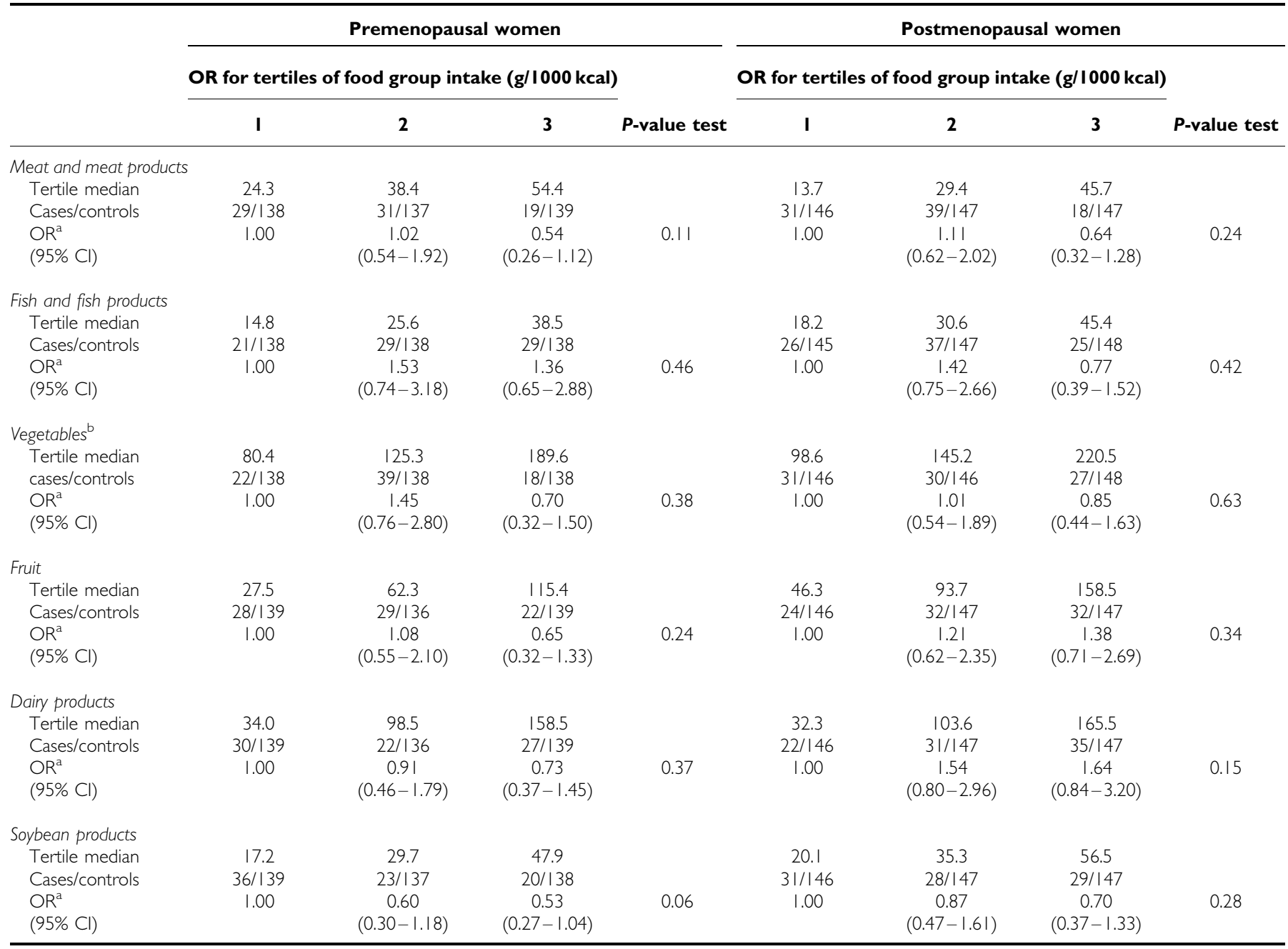

${ }^{a}$ Adjusted for age, motives for consultation, smoking, drinking, exercise, energy, family history, age at menarche, parity, age at first full-term pregnancy, BMl and age at menopause for postmenopausal women. ${ }^{b}$ Included both green-yellow vegetabeles and other vegetables. 
Odds ratios (ORs) and 95\% confidence intervals (Cls) for breast cancer according to soybean product intake by menopausal status

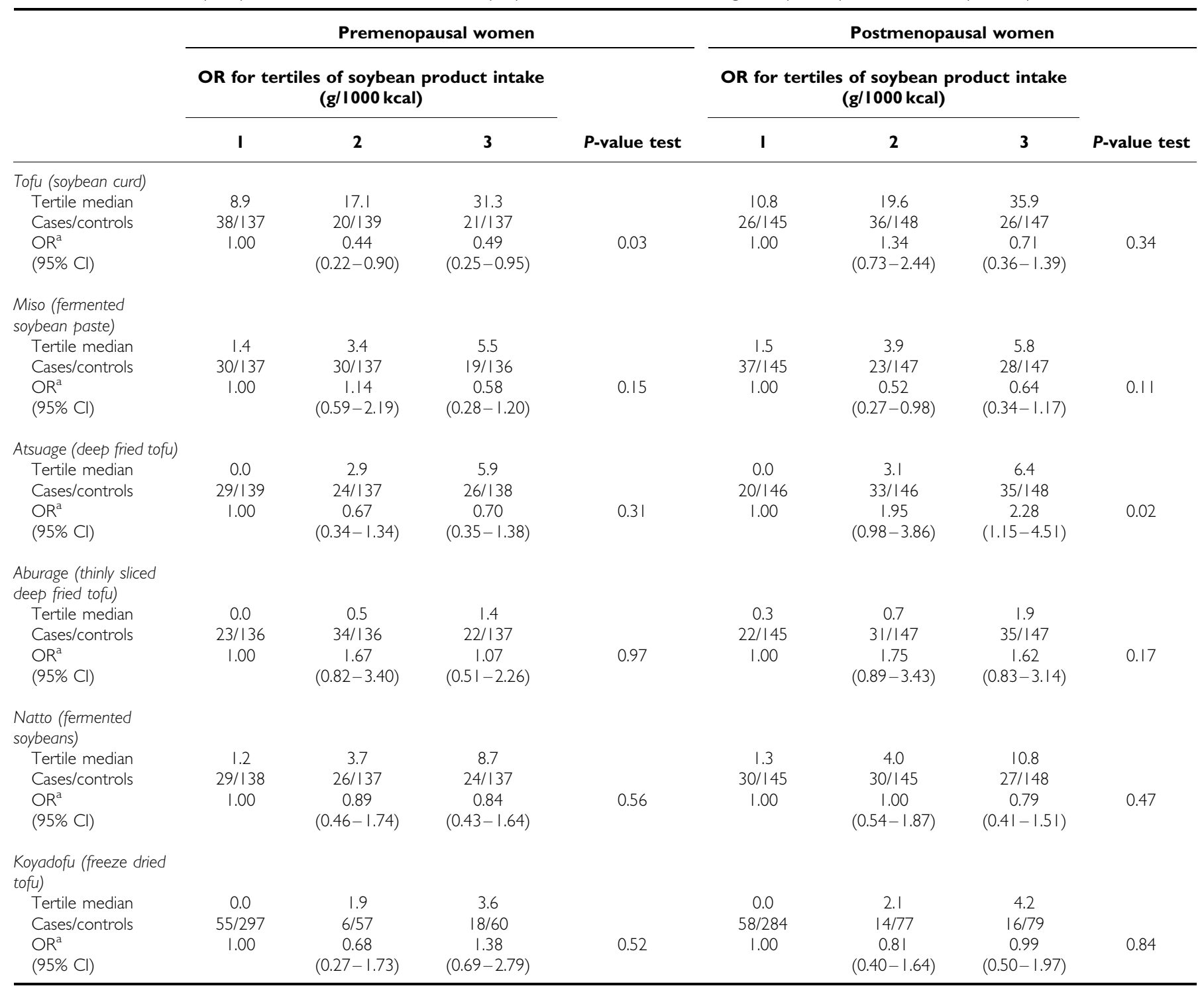

${ }^{a}$ Adjusted for age, motives for consultation, smoking, drinking, exercise, energy, family history, age at menarche, parity, age at first full-term pregnancy, BMI and age at menopause for postmenopausal women.

Soybean foods are rich in precursors of the isoflavone daidzein and genistein, which are heterocyclic phenols similar in structure to oestrogens, and it has been hypothesised that a high dietary intake of soybean products might reduce breast cancer risk by interfering with the action of endogenous oestradiol (Messina, 1999). The results are in line with the inverse association between intake of soybean products and breast cancer risk suggested from ecological/cross-sectional studies (Adlercreutz, 1995; Adlercreutz and Mazur, 1997), and also from analytical investigations. Thus, case-control studies have found that soybean food intake was associated with a decreased risk of breast cancer among premenopausal Singapore women (Lee et al, 1991), and both pre- and postmenopausal Asian-American women (Wu et al, 1996), although a Chinese case - control study failed to detect any protective effects of soybean food (Yuan et al, 1995). Cohort studies among Japanese (Hirayama, 1990; Yamamoto et al, 2003), Japanese-American (Nomura et al, 1978) and Caucasian-American women (Greenstein et al, 1996) have also provided some evidence that soybean products may reduce the risk of breast cancer. A prospective study conducted in Japan, however, found no link between soya consumption and breast cancer risk, but in this case the subjects were city residents in Hiroshima or Nagasaki exposed to high doses of ionising radiation and therefore the cohort was unusual (Key et al, 1999). A recent cohort study based on public health center in Japan (Yamamoto et al, 2003) found frequent miso soup and isoflavone consumption to be associated with a reduced risk of breast cancer and the protective effect was stronger in postmenopausal women. However, the FFQ applied included only two items for soybean-ingredient foods (i.e. miso soup and soyfoods), making it impossible to investigate differences in effects among types of soybean-ingredient foods.

Isoflavone intake by Japanese is much higher than that by Western populations (Jones et al, 1989; Kimira et al, 1998). Tofu, miso and natto were main foods containing rich isoflavones. Attributable rate of genistein were tofu (49.6\%), miso (20.9\%), natto (14.7\%) among Japanese. In the present study, tofu was protective in premenopausal women, while atsuage and aburage, deep fried tofu containing much oil, was associated with elevated risk among postmenopausal women. This may be due to fat intake, which can exert an influence on the development of breast cancer among postmenopausal women. Some studies have suggested that high intake of soybean products in premenopausal women may 
Table 5 Odds ratios (ORs) and 95\% confidence intervals (Cls) for breast cancer according to isoflavone intake by menopausal status

Premenopausal women

OR for tertiles of isoflavone intake $(\mathrm{mg} / \mathrm{l} 000 \mathrm{kcal})$

Postmenopausal women

OR for tertiles of isoflavone intake $(\mathrm{mg} / \mathrm{l} 000 \mathrm{kcal})$

\begin{tabular}{|c|c|c|c|c|c|c|c|c|}
\hline & I & 2 & 3 & $P$-value test & $\mathbf{I}$ & 2 & 3 & $P$-value test \\
\hline Cases/controls & $36 / 138$ & 24/139 & 19/137 & & $33 / 145$ & 29/144 & 26/151 & \\
\hline $\begin{array}{l}\mathrm{OR}^{\mathrm{a}} \\
(95 \% \mathrm{Cl})\end{array}$ & 1.00 & $\begin{array}{c}0.62 \\
(0.32-1.20)\end{array}$ & $\begin{array}{c}0.44 \\
(0.22-0.89)\end{array}$ & 0.02 & 1.00 & $\begin{array}{c}0.76 \\
(0.41-1.40)\end{array}$ & $\begin{array}{c}0.58 \\
(0.30-1.10)\end{array}$ & 0.09 \\
\hline
\end{tabular}

${ }^{a}$ Adjusted for age, motives for consultation, smoking, drinking, exercise, energy, family history, age at menarche, parity, age at first full-term pregnancy, BMI and age at menopause for postmenopausal women.

reduce serum oestradiol concentrations, suppress the mid-cycle surge of gonadotropins, and perhaps increase the length of the menstrual cycle (Cassidy et al, 1994; Lu et al, 1996; Nagata et al, 1997).

There is increasing evidence that dietary factors may play a role in the production, metabolism, and bioavailability of sex hormones. Soy-containing diets have long been known to be typical of some ethnic groups who experience low breast cancer risk. Soybeans contain a significant amount of the isoflavones daidzein and genistein, which may exert antioestrogenic effects and protect epithelial tissue from stimulation by endogenous oestrogens. There are several possible mechanisms by which soy isoflavones specifically may modulate the risk of breast carcinoma: (1) increase of serum levels of sex hormone-binding globulin (SHBG) (Adlercreutz et al, 1991; Mousavi and Adlercreutz, 1993); (2) downregulation of enzymes involved in oestrogen biosynthesis, such as aromatase (Adlercreutz et al, 1993); (3) inhibition of $17 \beta$ hydroxysteroid dehydrogenase type I (Makela et al, 1995); (4) suppression of the gonadotorpins follicule stimulating hormone (FSH) and luteinising hormone (LH); (5) change in intestinal flora, which affect reabsorption of E2 and lower circulating oestrogen levels (Adlercreutz, 1998). Studies examining the effect of a soy protein diet on the menstrual cycle have demonstrated a significant increase in follicular phase length and delay in menstruation, including suppression of midcycle surges of $\mathrm{LH}$ and $\mathrm{FSH}$, which potentially may reduce the risk of breast cancer (Cassidy et al, 1994; Lu et al, 1996; Nagata et al, 1998; Kumar et al, 2002). Isoflavones have in fact received a great deal of attention due to their antiproliferative properties and these would support the protective effect against breast cancer in premenopausal women observed in the present study. However, clarification of effects in postmenopausal women is still required. In this context it is of interest that isoflavones may exert both oestrogenic and antioestrogenic properties after modification by intestinal bacteria.

Soybeans are a unique dietary source of a group of phytochemicals and several natural anticarcinogens have now been identified in soybeans, such as protease inhibitors, phytates, phytosterols, saponins and lignans. Also, soybeans are an excellent source of dietary fibre and micronutrients, especially calcium. It will be important in future epidemiological studies to investigate the association between intake of soybean products and breast cancer by obtaining a more complete assessment of soybean intake. Further studies are required to confirm the ability of the nutritional profile of soybeans to reduce the risk of breast cancer.

Potential limitations of the present study should be considered. One methodological issue is selection of base population for controls. We applied noncancer patients at ACCH as controls because it is reasonable to assume our cases arise within this population base. Main reasons to visit at ACCH among cases and controls were self/family recommendation, referral from other clinics, and secondary screening after primary screening. Although distributions of these reasons slightly differ, it was considered in statistical analyses. Notable point of our control population is its similarity to general population in terms of exposure of interest, here dietary pattern. We have compared lifestyle characteristics between outpatients in ACCH and the 1231 individuals randomly selected from the general population, and confirmed that they are not substantially different (Inoue et al, 1997). Possible bias due to medical background of controls is another potential source of bias; however, our previous report revealed substantially limited impact of it. More than $66 \%$ of noncancer outpatients at ACCH did not have any specific medical condition. Remaining $34 \%$ of them have specific diseases, but common part of them were benign tumours and/or non-neoplastic polyps (13.1\%), mastitis (7.5\%), digestive disease $(4.1 \%)$, or benign gynaecological disease $(4.1 \%)$ (Hamajima et al, 1995). This situation is very different from that in the US, where people visit local general clinics first, and are then referred to hospitals, which function as secondary and/or specific facilities for further medical treatment. We therefore conclude that it is feasible to use noncancer outpatients as controls in epidemiological studies with due consideration of age, sex, season, and reason for visit. The present study was free of recall information bias to the questionnaire because all data were collected prior to diagnoses. Eligible controls were not matched, because our previous study showed that the large number of nonselsected controls gives a steadier estimate than selected, matched controls (Hamajima et al, 1994).

Another limitation of the present study included the small number of cases that are more likely to be due to chance leading to a false-positive result. Conversely, small sample may lack sufficient power to detect significant differences. The powers for detection of the OR of 0.5 for higher $v s$ lower level of total isoflavone intake were $77 \%$ among premenopausal women and $81 \%$ among postmenopausal women, respectively (alpha error $=0.0500$, twosided). Much larger studies will be required to confirm the impact of soybean products and isoflavone intake on breast cancer risk among Japanese women.

A number of risk factors for breast cancer have been established, most of them related to reproductive events. Evidence from studies of migrant populations, however, has also implicated environmental or lifestyle factors as being of importance and the diet is suspected of playing a role. The present study focused on the Japanese diet, which features a high level of consumption of soybean products and was able to demonstrate that high consumption of soybean products reduces the risk in Japanese premenopausal women. The findings are biologically plausible and suggested a potential beneficial effect of soybean products and isofloavones in the prevention of breast cancer.

\section{ACKNOWLEDGEMENTS}

We thank all the doctors, nurses, technical staff and hospital business staff of Aichi Cancer Center Hospital for the daily 
administration of the HERPACC study. We are greatly indebted to the staff of the Department of Breast Surgery, Aichi Cancer Center Hospital for their support and helpful discussions. We are also grateful to Ms H Fujikura, Ms K Asai, Ms K Fukaya, Ms M Obuchi, Ms C Adachi and Ms K Sanji for data collection and preparation.
This work was supported in part by a Grant-in-Aid for Cancer Research from the Japanese Ministry of Health, Labor and Welfare and a Grant-in-Aid for Scientific Research on Special Priority Areas of Cancer from the Japanese Ministry of Education, Culture, Sports, Science and Technology.

\section{REFERENCES}

Adlercreutz H (1990) Western diet and western disease: some hormonal and biochemical mechanisms and associations. Scand J Clin Lab Invest 50(Suppl): 3-23

Adlercreutz H (1995) Phytoestrogens: epidemiology and a possible role in cancer protection. Environ Health Perspect 103: $103-112$

Adlercreutz H (1998) Evolution, nutrition, intestinal microflora, and prevention of cancer: a hypothesis. Proc Soc Exp Bio Med 217: $241-246$

Adlercreutz H, Bannwart C, Wahala K, Makeia T, Brunow G, Hase T, Arosemena PJ, Kellis J, Vickery LE (1993) Inhibition of human aromatase by mammalian lignans and isoflavonoid phytoestrogens. J Steroid Biochem Mol Biol 44: 147 - 153

Adlercreutz H, Honjo H, Higashi A, Fotsis T, Hamalainen E, Hasegawa T, Okada H (1991) Urinary excretion of lignans and isoflavonoid phytoestrogens in Japanese men and women consuming a traditional Japanese diet. Am J Clin Nutr 54: 1093-1100

Adlercreutz H, Mazur W (1997) Phyto-oestrogens and Western diseases. Ann Med 29: $95-120$

Cassidy A, Bingham S, Setchell KDR (1994) Biological effects of a diet of soy protein rich in isoflavones on the menstrual cycle of premenopausal women. Am J Clin Nutr 60: 333-340

Greenstein J, Kushi L, Zheng W, Fee R, Campbel D, Sellers T, Folsom A (1996) Risk of breast cancer associated with intake of specific foods and food groups. Am J Epidemiol 143: S36

Hamajima N, Hirose K, Inoue M, Takezaki T, Kuroishi T, Tajima K (1995) Age-specific risk factors of breast cancer estimated by a case-control study in Japan. J Epidemiol 5: 99-105

Hamajima N, Hirose K, Inoue M, Takezaki T, Kuroishi T, Tajima K (1994) Case-control studies: matched controls or all available controls ? J Clin Epidemiol 47: 971 - 975

Hirayama T (1990) Life-style and mortality: a large-scale census-based cohort study in Japan. In Contributions to Epidemiology and Biostatistics Wahrendorf J (ed) Swizerland: Karger

Hirose K, Tajima K, Hamajima N, Inoue M, Takezaki T, Kuroishi K, Yoshida M, Tokudome S (1995) A large-scale, hospital-based casecontrol study of risk factors of breast cancer according to menopausal status. Jpn J Cancer Res 86: 146-154

Hirose K, Tajima K, Hamajima N, Takezaki T, Inoue M, Kuroishi T, Miura S, Tokudome S (1999) Effect of body size on breast-cancer risk among Japanese women. Int J Cancer 80: 349-355

Hirose K, Tajima K, Hamajima N, Takezaki T, Inoue M, Kuroishi T, Miura S, Tokudome S (2001) Association of family history and other risk factors with breast cancer risk among Japanese premenopausal and postmenopausal women. Cancer Causes Control 12: 349-358

Imaeda N, Fujiwara N, Tokudome Y, Ikeda M, Kuriki K, Nagaya T, Sato J, Goto C, Maki S, Tokudome S (2002) Reproducibility of a semiquantitative food frequency questionnaire in Japanese female dietitians. J Epidemiol 12: $45-53$

Inoue $\mathrm{M}$, Tajima K, Hirose $\mathrm{K}$, Hamajima $\mathrm{N}$, Takezaki T, Kurosihi $\mathrm{T}$, Tominaga S (1997) Epidemiological features of first-visit outpatients in Japan: comparison with general population and variation by sex, age, and season. J Clin Epidemiol 50: 69-77

Jones AE, Price KR, Fenwick GR (1989) Development and application of a high-performance liquid chromatographic method for the analysis of phytoestorgens. J Sci Food Agric 46: $357-364$

Key TJ, Sharp GB, Appleby PN, Beral V, Goodman MT, Soda M, Mabuchi K (1999) Soya foods and breast cancer risk: a prospective study in Hiroshima and Nagasaki, Japan. Br J Cancer 81: $1248-1256$

Kimira M, Arai Y, Shimoi K, Watanabe W (1998) Japanese intake of flavonoids and isoflavonoids from foods. J Epidemiology 8: $168-175$

Kumar NG, Cantor A, Allen K, Riccardi D, Cox CE (2002) The specific role of isoflavones on estrogen metabolism in premenopausal women. Cancer 94: $1166-1174$
Lee HP, Gourley L, Duffy SW, Esteve J, Lee J, Day NE (1991) Dietary effects on breast-cancer risk in Singapore. Lancet 337: $1197-1200$

Lu L-JW, Anderson KE, Grady JJ, Nagamani M (1996) Effects of soya consumption for one month on steroid hormones in premenopausal women: implications for breast cancer risk reduction. Cancer Epidemiol Biomarkers Prev 5: $63-70$

Makela S, Poutanen M, Lehtimaki J, Kostian ML, Santti R, Vihko R (1995) Estrogen-specific 17 $\beta$-hydroxysteroid oxidoreductase type I (E.C.1.1.1.62) as a possible target for the action of phytoestrogens. Proc Soc Exp Biol Med 208: 51 - 59

Messina M (1999) Legumes and soybeans: overview of their nutritional profiles and health effects. Am J Clin Nutr 70(Suppl): 439s-450s

Messina M, Barnes S (1991) The role of soy products in reducing risk of cancer. J Natl Cancer Inst 83: 541 - 546

Mousavi Y, Adlercreutz H (1993) Genistein is an effective stimulator of sex hormone-binding globulin production in hepatocarcinoma human liver cancer cells and suppresses proliferation of these cells in culture. Steroids 58: $301-304$

Nagata C, Kabuto M, Kurisu Y, Shimizu H (1997) Decreased serum estradiol concentration associated with high dietary intake of soy products in premenopausal Japanese women. Nutr Cancer 29: $228-233$

Nagata C, Takatsuka N, Inaba S, Kawakami N, Shimizu H (1998) Effect of soymilk consumption on serum estrogen concentration in premenopausal Japanese women. J Natl Cancer Inst 90: 1830-1835

Nomura A, Henderson BE, Lee J (1978) Breast cancer and diet among the Japanese in Hawaii. Am J Clin Nutr 31: 2020-2025

Parkin DM, Whelan SL, Ferlay J, Raymond L, Young J (1997) Cancer Incidence in Five Continents Vol. VII, IARC Scientific Publication 143. Lyon: IARC

Science and Technology Agency, Japan (1994) Follow-up of Standard Tables of Food Composition in Japan. Tokyo: Ishiyaku Shuppan (in Japanese)

Science and Technology Agency, Japan (2001) Standard Tables of Food Composition in Japan 5th edn Tokyo: Ministry of Finance (in Japanese)

Stampfer MJ, Willett WC, Colditz GA, Speizer FE (1987) Intake of cholesterol, fish and specific types of fat in relation to risk of breast cancer. In Proceedings of the AOCS Short Course on Polyunsaturated Fatty Acids and Eicosanoids Lands WE (ed) pp 248-252. Champaign, IL: American Oil Chemists' Society Press

Tajima K, Hirose K, Inoue M, Takezaki T, Hamajima N, Kuroishi T (2000) A model of practical cancer prevention for out-patients visiting a hospital: the Hospital-based Epidemiologic Research Program at Aichi Cancer Center (HERPACC). Asian Pacific J Cancer Prev 1: $35-47$

Tokudome S, Ikeda M, Tokudome Y, Imaeda N, Kitagawa I, Fujiwara N (1998) Development of data-based semi-quantitative food frequency questionnaire for dietary studies in middle-aged Japanese. Jpn J Clin Oncol 28: $679-687$

Tokudome S, Imaeda N, Tokudome Y, Fujiwara N, Nagaya T, Sato J, Kuriki K, Ikeda M, Maki S (2001) Relative validity of a semi-quantitative food frequency questionnaire versus 28 day weighted diet records in Japanese female dietitians. Eur J Clin Nutr 55: $732-742$

Toniolo P, Riboli E, Shore RE, Pasternak BS (1994) Consumption of meat, animal products, protein, and fat and risk of breast cancer: a prospective cohort study in New York. Epidemiology 5: 391-397

Vatten LJ, Solvoll K, Loken EB (1990) Frequency of meat and fish intake and risk of beast cancer in a prospective study of 14,500 Norwegian women. Int J cancer 46: $12-15$

Willett WC (1997) Specific fatty acids and risks of breast and prostate cancer: dietary intake. Am J Clin Nutr 66(Suppl): 1557s-1563s 
Wu AH, Ziegler RG, Horn-Ross PL, Nomura AM, West DW, Kolonel LN, Rosenthal JF, Hoover RN, Pike MC (1996) Tofu and risk of breast cancer in Asian-Americans. Cancer Epidemiol Biomark Prev 5: 901 - 906

Yamamoto S, Sobue T, Kobayashi M, Sasaki S, Tsugane S (2003) Soy, isoflavones, and breast cancer risk in japan. J Natl Cancer Inst 95: 906 -913

Yoo K-Y, Tajima K, Kuroishi T, Hirose K, Yoshida M, Miura S, Murai S (1992) Independent protective effect of lactation against breast cancer: a case - control study in Japan. Am J Epidemiol 135: 726-733

Yuan JM, Wang QS, Ross RK, Henderson BE, Yu MC (1995) Diet and breast cancer in Shanghai and Tianjin, China. Br J Cancer 71: 1353-1358 